\title{
Analysis of Pharmacokinetic/Pharmacodynamic Parameters and Dosage Regimen of Posaconazole against Candida spp. and Aspergillus spp. Using Monte Carlo Simulation
}

\author{
Ying Wang1, Jingyi Zhao², Junhui Hu', Xinhong Zhao', Yinhui Yao1* \\ ${ }^{1}$ Department of Pharmacy, Affiliated Hospital of Chengde Medical College, Chengde, China \\ ${ }^{2}$ Department of Functional Center, Chengde Medical College, Chengde, China \\ Email: *yhyaodrdr@163.com
}

How to cite this paper: Wang, Y., Zhao, J.Y., Hu, J.H., Zhao, X.H. and Yao, Y.H. (2020) Analysis of Pharmacokinetic/Pharmacodynamic Parameters and Dosage Regimen of Posaconazole against Candida spp. and Aspergillus spp. Using Monte Carlo Simulation. Pharmacology \& Pharmacy, 11, 17-28.

https://doi.org/10.4236/pp.2020.111003

Received: December 16, 2019

Accepted: January 14, 2020

Published: January 17, 2020

Copyright $\odot 2020$ by author(s) and Scientific Research Publishing Inc. This work is licensed under the Creative Commons Attribution International License (CC BY 4.0).

http://creativecommons.org/licenses/by/4.0/

\section{(c) (i) Open Access}

\begin{abstract}
Invasive fungal infections (IFI) have recently become increasingly more prevalent, resulting in an increased risk of morbidity and mortality. Both Candida spp. and Aspergillus spp. are major causes of IFI. In this study, we aimed to evaluate the cumulative fraction of response of various dosage regimens of posaconazole against nine Candida spp. and six Aspergillus spp. in both children and adults. Monte Carlo simulation (MCS) was performed to optimize selection of posaconazole dosage regimens. For children, a dosage regimen of $120 \mathrm{mg} / \mathrm{m}^{2}$ posaconazole tid was sufficient to treat fungal infections caused by all six Aspergillus spp. and six of the nine Candida spp. (but was not effective against $C$. glabrata, $C$. guilliermondii and $C$. krusei). In contrast, a $400 \mathrm{mg}$ dosage regimen of posaconazole bid achieved the target pharmacokinetic/pharmacodynamics (PK/PD) parameters against all six Aspergillus spp. and eight of the nine Candida spp. (but was not effective against $C$. glabrata) in the adults. Dosage regimens of $50 \mathrm{mg}$ bid, $100 \mathrm{mg}$ bid, or $200 \mathrm{mg}$ bid were not effective. Posaconazole dosage regimens are likely to achieve their desired PK/PD targets against Candida spp. and Aspergillus spp. in both children and adults.
\end{abstract}

\section{Keywords}

Posaconazole, Monte Carlo Simulation, Candida spp., Aspergillus spp.,

Pharmacokinetics/Pharmacodynamics

\section{Introduction}

Invasive fungal infections (IFI) have recently become increasingly more preva- 
lent, resulting in an increased risk of morbidity and mortality, mainly due to increasing numbers of immunosuppressed and cancer patients [1]. Both Candida spp. and Aspergillus spp. are major causes of IFI. Candida is the most common cause of IFI in critically ill and surgery patients. Invasive Aspergillosis has become more common in immunocompromised patients such as hematology-oncology patients, patients undergoing hematopoietic stem cell transplants, and solid organ transplant recipients [2] [3].

Although numerous antifungal agents have been used as prophylactics in high-risk patients, there are many limitations to these drugs. Amphotericin B deoxycholate is associated with infusion-related toxicity and dose-dependent nephrotoxicity. Furthermore, 5-fluocytosine and fluconazole have a narrow therapeutic index, whereas itraconazole has many clinically relevant drug adverse interactions. Echinocandins are only available as intravenous formulations, which hinders their clinical application [4]. Thus, these limitations have driven the need for new, more effective antifungal agents.

Posaconazole is categorized as a broad-spectrum triazole antifungal agent with potent in vitro and in vivo activities against a large number of clinically important yeasts and models [4] [5]. Posaconazole dissolves readily in lipids, is orally absorbed, and distributes significantly throughout the tissues. However, the dosage regimen can significantly influence the relative bioavailability of posaconazole, which can also be significantly increased by the administration of high-fat containing food [6] [7] [8]. The pharmacokinetics of posaconazole administered by oral suspension is characterized by low bioavailability, unpredictable plasma concentrations, and large inter-individual patient variability [9]. Assessing various dosage regimens is necessary to better understand differences in clinical response.

To maximize the likelihood of favorable clinical outcomes and minimize the probability of antimicrobial resistance, Monte Carlo simulation (MCS) is a very useful tool for determining the appropriate dose in most therapeutic areas [10] [11] [12] [13] [14]. MCS can be implemented to evaluate antifungal agent dosage regimens to integrate variables including pharmacokinetic (PK) parameters, minimum inhibitory concentration (MIC) distribution, and pharmacodynamic (PD) information. MCS is not only applied to many kinds of antimicrobial agents, but also applied to MIC breakpoints [15] [16] [17]. For example, Mouton JW et al. reveal the provisional breakpoint of BAL9141 is S (susceptible) $<4$ $\mathrm{mg} /$ liter using MCS [16]. Doan TN et al. investigate the probability of target attainment (PTA) of various anidulafungin dosing regimens against Candida spp. in patients with acute leukaemia using MCS [15]. Therefore, we aimed to optimize selection of posaconazole dosage regimens by evaluating the probability of attaining target PD exposure against a wide range of clinical isolates of Candida spp. and Aspergillus spp. using MCS.

\section{Materials and Methods}

\subsection{Pharmacokinetics}

Information regarding the pharmacokinetic parameters of posaconazole was 
obtained from published studies [18] [19]. Phase 1 studies were randomized and double-blind, and consisted of a placebo-controlled group and a parallel-group. Male and female volunteers ranging in age from 19 to 43 were randomly assigned to either receive treatment with posaconazole oral tablets (50 to $400 \mathrm{mg}$ ) or placebo tablets to be taken twice daily for 14 days [18]. Pharmacokinetic data of children aged 13 years or younger suffering from a hematologic malignancy were treated prophylactically with posaconazole oral suspension at a dose of 120 $\mathrm{mg} / \mathrm{m}^{2}$ three times daily, as reported by Vanstraelen $\mathrm{K}$ [19]. Information from studies that evaluated clinically relevant dosage regimens and provided the mean results for the pharmacokinetic parameters of interest with corresponding measures of variability of areas under the concentration-time curve at steady-state (AUCs) were included (Table 1).

\subsection{Minimum Inhibition Concentration (MIC) Distribution of Candida spp. and Aspergillus spp.}

The EUCAST MIC distribution website (http://www.eucast.org; last accessed March 13, 2017) was utilized to obtain MIC distribution data for Candida spp. (Table 2). MIC distribution data for Aspergillus spp. were gathered in five independent laboratories in Europe and the United States and tested using the Clinical and Laboratory Standards Institute (CLSI) broth microdilution method (M38-A2 document) (Table 3).

Table 1. Summary of posaconazole pharmacokinetic parameters following its administration in children.

\begin{tabular}{|c|c|c|c|c|}
\hline Patient population & \multicolumn{4}{|c|}{$\mathrm{AUC}_{0-24}(\mathrm{mg} \cdot \mathrm{h} / \mathrm{L})$} \\
\hline Children & \multicolumn{4}{|c|}{$\begin{array}{c}120 \mathrm{mg} / \mathrm{m}^{2} \text { tid } \\
20.5 \pm 14.0^{\mathrm{a}}\end{array}$} \\
\hline Adults & $\begin{array}{l}50 \mathrm{mg} \text { bid } \\
8.29(36)^{\mathrm{b}}\end{array}$ & $\begin{array}{l}100 \mathrm{mg} \text { bid } \\
21.78(40)^{\mathrm{b}}\end{array}$ & $\begin{array}{l}200 \mathrm{mg} \text { bid } \\
31.11(26)^{\mathrm{b}}\end{array}$ & $\begin{array}{l}400 \mathrm{mg} \text { bid } \\
73.11(20)^{\mathrm{b}}\end{array}$ \\
\hline
\end{tabular}

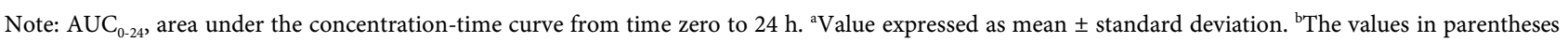
are the percentage coefficient of variance $(\mathrm{CV} \%)$.

Table 2. Frequency distribution of the MIC of posaconazole for Candida spp. from the EUCAST MIC distribution website.

\begin{tabular}{|c|c|c|c|c|c|c|c|c|c|c|c|c|c|c|}
\hline \multirow{2}{*}{ Species } & \multirow{2}{*}{$\mathrm{n}$} & \multicolumn{13}{|c|}{$\mathrm{MIC}(\mu \mathrm{g} / \mathrm{ml})$} \\
\hline & & 0.008 & 0.016 & 0.03 & 0.06 & 0.125 & 0.25 & 0.5 & 1 & 2 & 4 & 8 & 16 & 32 \\
\hline C. albicans & 5297 & 3.15 & 64.73 & 21.92 & 7.02 & 1.59 & 0.64 & 0.36 & 0.08 & 0 & 0.06 & 0.21 & 0.25 & 0 \\
\hline C. dubliniensis & 74 & 0 & 70.27 & 22.97 & 6.76 & 0 & 0 & 0 & 0 & 0 & 0 & 0 & 0 & 0 \\
\hline C. glabrata & 1487 & 0.13 & 0.74 & 1.48 & 8.88 & 20.85 & 25.69 & 21.18 & 8.81 & 4.24 & 3.70 & 3.43 & 0.13 & 0.74 \\
\hline C. guilliermondii & 153 & 0 & 2.61 & 15.03 & 32.03 & 24.83 & 16.34 & 4.58 & 1.31 & 1.31 & 0 & 0 & 1.96 & 0 \\
\hline C. kefyr & 28 & 3.57 & 32.14 & 21.43 & 32.14 & 3.57 & 3.57 & 3.57 & 0 & 0 & 0 & 0 & 0 & 0 \\
\hline C. krusei & 362 & 0 & 0.83 & 7.46 & 25.14 & 42.27 & 20.44 & 3.87 & 0 & 0 & 0 & 0 & 0 & 0 \\
\hline C. Iusitaniae & 43 & 0 & 79.07 & 18.60 & 0 & 2.33 & 0 & 0 & 0 & 0 & 0 & 0 & 0 & 0 \\
\hline C. tropicalis & 1212 & 1.65 & 57.59 & 27.31 & 11.96 & 0.91 & 0.33 & 0.17 & 0 & 0 & 0.082 & 0 & 0 & 0 \\
\hline C. parapsilosis & 754 & 0.93 & 47.61 & 33.55 & 8.49 & 2.12 & 1.72 & 0.40 & 0.40 & 1.33 & 1.33 & 0.93 & 1.19 & 0 \\
\hline
\end{tabular}

MIC, Minimum Inhibitory Concentration; EUCAST, European Committee on Antimicrobial Susceptibility Testing. 
Table 3. Frequency distribution of the MIC of posaconazole for Aspergillus spp.

\begin{tabular}{|c|c|c|c|c|c|c|c|c|c|c|c|c|c|}
\hline \multirow{2}{*}{ Species } & \multirow{2}{*}{$\mathrm{n}$} & \multicolumn{12}{|c|}{$\mathrm{MIC}(\mu \mathrm{g} / \mathrm{ml})$} \\
\hline & & $\leq 0.01$ & 0.03 & 0.06 & 0.125 & 0.25 & 0.5 & 1 & 2 & 4 & 8 & 16 & 32 \\
\hline A. fumigatus & 1647 & 6.38 & 25.62 & 26.11 & 21.31 & 13.96 & 5.83 & 0.73 & 0 & 0.06 & 0 & 0 & 0 \\
\hline A. flavus & 321 & 0 & 9.97 & 41.12 & 26.17 & 17.45 & 4.05 & 0.62 & 0.62 & 0 & 0 & 0 & 0 \\
\hline A. terreus & 330 & 0 & 5.76 & 15.76 & 27.58 & 38.18 & 12.42 & 0 & 0.30 & 0 & 0 & 0.30 & 0.91 \\
\hline A. niger & 325 & 0 & 4.62 & 11.08 & 23.69 & 18.77 & 38.77 & 1.23 & 1.85 & 0 & 0 & 0 & 0 \\
\hline A. nidulans & 129 & 0 & 13.95 & 11.63 & 6.98 & 34.88 & 17.05 & 13.18 & 1.55 & 0 & 0.78 & 0 & 0 \\
\hline A. versicolor & 41 & 0 & 9.76 & 7.32 & 14.63 & 21.95 & 31.71 & 4.88 & 0 & 7.32 & 2.44 & 0 & 0 \\
\hline
\end{tabular}

\subsection{Monte Carlo Simulation}

A pharmacodynamic study of posaconazole in a murine model of disseminated Candidiasis demonstrated that the free-drug ratio of AUC/MIC at $24 \mathrm{~h} \geq 16.9$ was the critical predictor of response to posaconazole therapy [20]. Furthermore, the free-drug posaconazole AUC/MIC ratio PD target at 24 hours was 1.09 for the wild-type and mutant isolates of Aspergillus in an in vivo model of invasive pulmonary Aspergillosis [21]. The free-drug AUC/MIC ratios of posaconazole at 24 hours for other pharmacodynamic targets of Candidiasis (6 - 30) and Aspergillus $(0.4$ - 2) were also displayed for each MCS.

The pharmacokinetic parameters were determined to as the lognormal distribution obtained with a mean and a percentage coefficient of variance (CV\%). In the case of MIC, the data obtained from Candida spp. and Aspergillus spp. were assumed to follow a discrete distribution. Posaconazole protein binding was set at a constant value of $98 \%$ [6]. CrystalBall software (Fusion Edition, version 11.1.2.4.600, Oracle) was used for the Monte Carlo simulation consisting of 1000 subjects. The percentage of subjects who achieved the requisite pharmacodynamic exposure $\left(f \mathrm{AUC}_{0-24} / \mathrm{MIC}\right)$ for each antibiotic dosage regimen/bacterial population combination is termed the probability of target attainment (PTA) [22]. The cumulative fraction of response (CFR) refers to the expected population PTA for a specific drug dose and a specific population of microorganisms [22].

The corresponding PTA of Candida spp. was determined at a fixed MIC value in the range of $0.008-32 \mu \mathrm{g} / \mathrm{ml}$. For the calculation of PTA (Aspergillus spp.), MIC values were fixed from 0.01 to $32 \mu \mathrm{g} / \mathrm{ml}$. Calculation of CFR was achieved using data based on the corresponding MIC distribution, whereby CFR values > $90 \%$ were considered optimal for a dosage regimen against a population of organisms.

\section{Results}

\subsection{PTA Analysis}

Figure 1 demonstrates the probability of PK/PD target attainment by MIC for posaconazole studied at the selected dosage regimens against Candida spp. and 
Aspergillus spp. in children and adults.

The selected targets for Candida spp. were $f \mathrm{AUC}_{0-24} / \mathrm{MIC} \geq 16.9$. Children $\left(120 \mathrm{mg} / \mathrm{m}^{2}\right.$, tid) and adults (50 mg, $100 \mathrm{mg}, 200 \mathrm{mg}, 400 \mathrm{mg}$, bid) achieved PTA values of $\geq 90 \%$ for MICs $\leq 0.06,0.03,0.125,0.25$ and $0.5 \mu \mathrm{g} / \mathrm{ml}$, respectively (Figure 1(a)). The chosen targets for Aspergillus spp. were $\mathrm{AAUC}_{0-24} / \mathrm{MIC} \geq 1.09$. Posaconazole dosage regimens of $50 \mathrm{mg}$ and $100 \mathrm{mg}$, tid, both resulted in PTA values of $\geq 90 \%$ for a $2 \mu \mathrm{g} / \mathrm{ml}$ MIC. Dosage regimens with children $\left(120 \mathrm{mg} / \mathrm{m}^{2}\right.$, tid) and adults (50 mg, $400 \mathrm{mg}$, bid) resulted in PTA values of $\geq 90 \%$ for MICs $\leq$ $1,0.5$, and $8 \mu \mathrm{g} / \mathrm{ml}$, respectively (Figure $1(\mathrm{~b})$ ).

\subsection{CFR Analysis}

Table 4 showed CFR assessment for different posaconazole dosage regimens. At a high $f \mathrm{AUC}_{0-24} / \mathrm{MIC}$ value of 16.9 in Candida spp., the corresponding CFRs of C. albicans, $C$. dubliniensis, $C$. lusitaniae, and $C$. tropicalis were greater than 95\%. Only C. parapsilosis had CFR values no higher that 90\%. CFRs in C. glabrata were lower than $90 \%$ with the following dosage regiments: $120 \mathrm{mg} / \mathrm{m}^{2}$, tid (38.04\%); $50 \mathrm{mg}$, bid (14.46\%); $100 \mathrm{mg}$, bid (43.35\%); $200 \mathrm{mg}$, bid (57.49\%); and $400 \mathrm{mg}$, bid (80.68\%). CFRs for C. guilliermondii with a dosage regimen of 400 mg bid was greater than $90 \%$. However, CFRs for $C$. guilliermondii with other dosage regimens varied from $51.17 \%$ to $89.89 \%$. In C. kefyr, the CFRs of 120 $\mathrm{mg} / \mathrm{m}^{2}$, tid (92.70\%); $100 \mathrm{mg}$, bid (94.39\%); $200 \mathrm{mg}$, bid (96.43\%); and $400 \mathrm{mg}$, bid (99.97\%) were greater than $90 \%$, but the CFR of $50 \mathrm{mg}$ bid $(86.52 \%)$ was less than $90 \%$. Posaconazole dosage regimens in C. krusei achieved $\geq 90 \%$ CFR at 200 $\mathrm{mg}$ bid (94.80\%) and $400 \mathrm{mg}$ bid (99.99\%), but $120 \mathrm{mg} / \mathrm{m}^{2}$ tid (73.30\%), $50 \mathrm{mg}$ bid $(39.15 \%)$, and $100 \mathrm{mg}$ bid $(83.15 \%)$ dosage regimens resulted in CFRs less than $90 \%$.

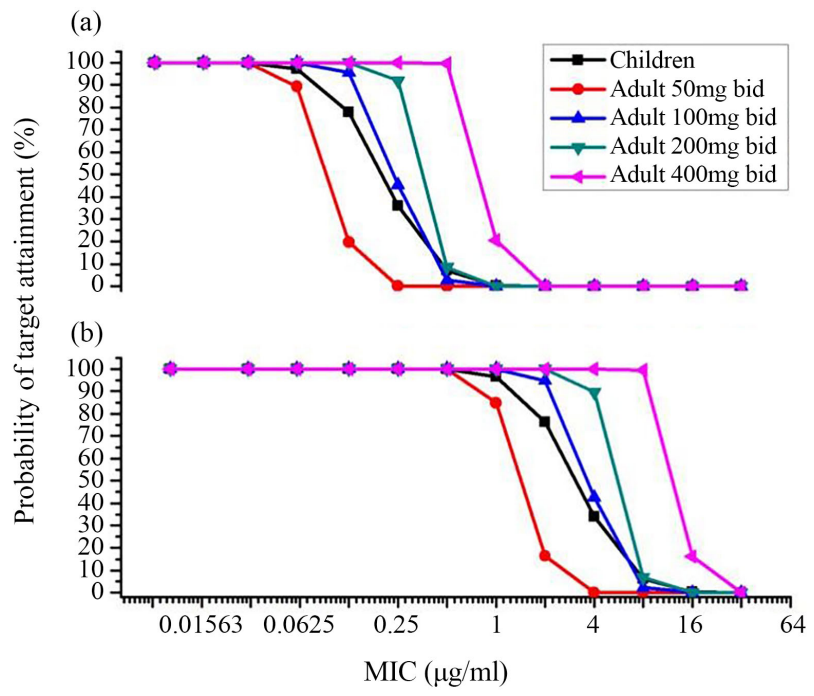

Figure 1. Probability of target attainment as a function of MIC for 10,000 simulated subjects being administered posaconazole. (a) The target was $f \mathrm{AUC}_{0-24} / \mathrm{MIC}>16.9$ against Candidiasis spp.; (b) the target was $\mathrm{AAUC}_{0-24} / \mathrm{MIC}>1.09$ against Aspergillosis spp. 
Table 4. Cumulative fraction of response (CFR) expectation values (\%) against nine Candida spp. and six Aspergillus spp. for each posaconazole dosage regimen in both children and adults.

\begin{tabular}{|c|c|c|c|c|c|}
\hline Species & $120 \mathrm{mg} / \mathrm{m}^{2}$ tid & $50 \mathrm{mg}$ bid & $100 \mathrm{mg}$ bid & $200 \mathrm{mg}$ bid & $400 \mathrm{mg}$ bid \\
\hline \multicolumn{6}{|l|}{ Candida spp. } \\
\hline C. albicans & 98.11 & 96.36 & 98.63 & 99.03 & 99.42 \\
\hline C. dubliniensis & 99.79 & 99.25 & 99.99 & 100 & 100 \\
\hline C. glabrata & 38.04 & 14.46 & 43.35 & 57.49 & 80.68 \\
\hline C. guilliermondii & 74.34 & 51.17 & 80.89 & 89.89 & 95.67 \\
\hline C. kefyr & 92.70 & 86.52 & 94.39 & 96.43 & 99.97 \\
\hline C. krusei & 73.30 & 39.15 & 83.15 & 94.80 & 99.99 \\
\hline C. lusitaniae & 99.47 & 98.12 & 99.89 & 100 & 100 \\
\hline C. tropicalis & 99.01 & 97.38 & 99.52 & 99.74 & 99.92 \\
\hline C. parapsilosis & 92.62 & 90.06 & 93.39 & 94.31 & 94.90 \\
\hline \multicolumn{6}{|l|}{ Aspergillus spp. } \\
\hline A. fumigatus & 99.92 & 99.81 & 99.96 & 99.99 & 100 \\
\hline A. flavus & 99.82 & 99.38 & 99.96 & 100 & 100 \\
\hline A. terreus & 99.90 & 99.72 & 99.98 & 100 & 100 \\
\hline A. niger & 99.44 & 98.22 & 99.91 & 100 & 100 \\
\hline A. nidulans & 98.40 & 95.89 & 99.15 & 99.27 & 99.99 \\
\hline A. versicolor & 92.64 & 89.47 & 93.42 & 96.97 & 99.99 \\
\hline
\end{tabular}

At a low AUC $_{0-24} / \mathrm{MIC}$ value of 1.09 in Aspergillus spp., the corresponding CFRs of $A$. fumigatus, $A$. flavus, $A$. terreus, $A$. niger and $A$. nidulans were greater than $95 \%$. The CFR of $50 \mathrm{mg}$ bid in $A$. versicolor was $89.47 \%$, but the remainder of dosage regimens resulted in CFRs greater than $90 \%$.

To increase the clinical relevance of this study, several PK/PD targets for Candida spp. (from 6 to 30) and Aspergillus spp. (from 0.4 to 2) were analyzed by Monte Carlo simulation to simulate species-specific CFR expectation values (Figure 2 and Figure 3). Increased PK/PD target values led to reduced CFR expectation values.

\section{Discussion}

In this study, we used MCS analysis to investigate the ability of posaconazole dosage regimens to achieve their requisite PK/PD target against nine Candida spp. and six Aspergillus spp. in both children and adults. Previous studies have demonstrated the efficacy of posaconazole against a variety of Candida spp. and Aspergillus spp. [23] [24] [25] [26]. The results of these simulations indicated that all of the dosage regimens simulated for children and adults were effective against five Candida spp. (C. albicans, C. dubliniensis, C. lusitaniae, C. tropicalis and C. parapsilosis) and five Aspergillus spp. (A. fumigatus, A. flavus, A. terreus, 
(a)

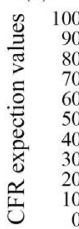

(c)

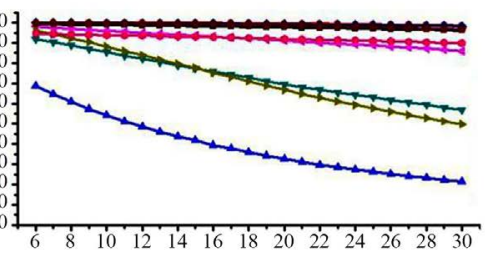

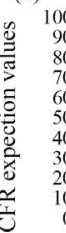

(e)

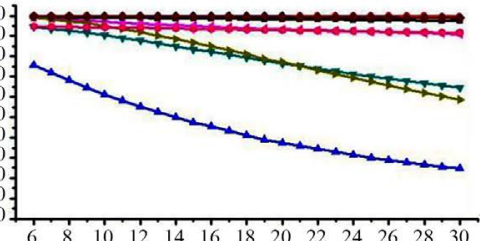

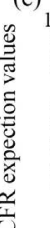

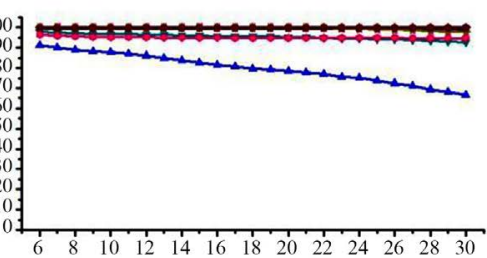

(b)

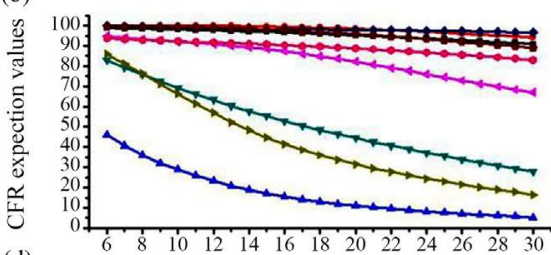

(d)

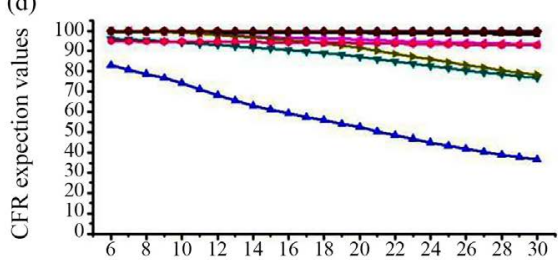

Figure 2. Cumulative fraction of response (CFR) expectation values of various posaconazole dosage regimens at various $\mathrm{AAUC}_{0-24} / \mathrm{MIC}$ (free-drug area under the plasma concentration-time curve from zero to $24 \mathrm{~h} /$ minimum inhibitory concentration) targets against nine Candidiasis spp. (C. albicans, C. dubliniensis, C. glabrata, C. guilliermondii, C. kefyr, C. krusei, C. lusitaniae, C. tropicalis and $C$. parapsilosis) in children and adults. The $\mathrm{X}$ axis label was $f \mathrm{AUC}_{0-24} / \mathrm{MIC}$ targets. (a) $120 \mathrm{mg} / \mathrm{m}^{2}$ tid; (b) $50 \mathrm{mg}$ bid; (c) $100 \mathrm{mg}$ bid; (d) $200 \mathrm{mg}$ bid; (e) $400 \mathrm{mg}$ bid.
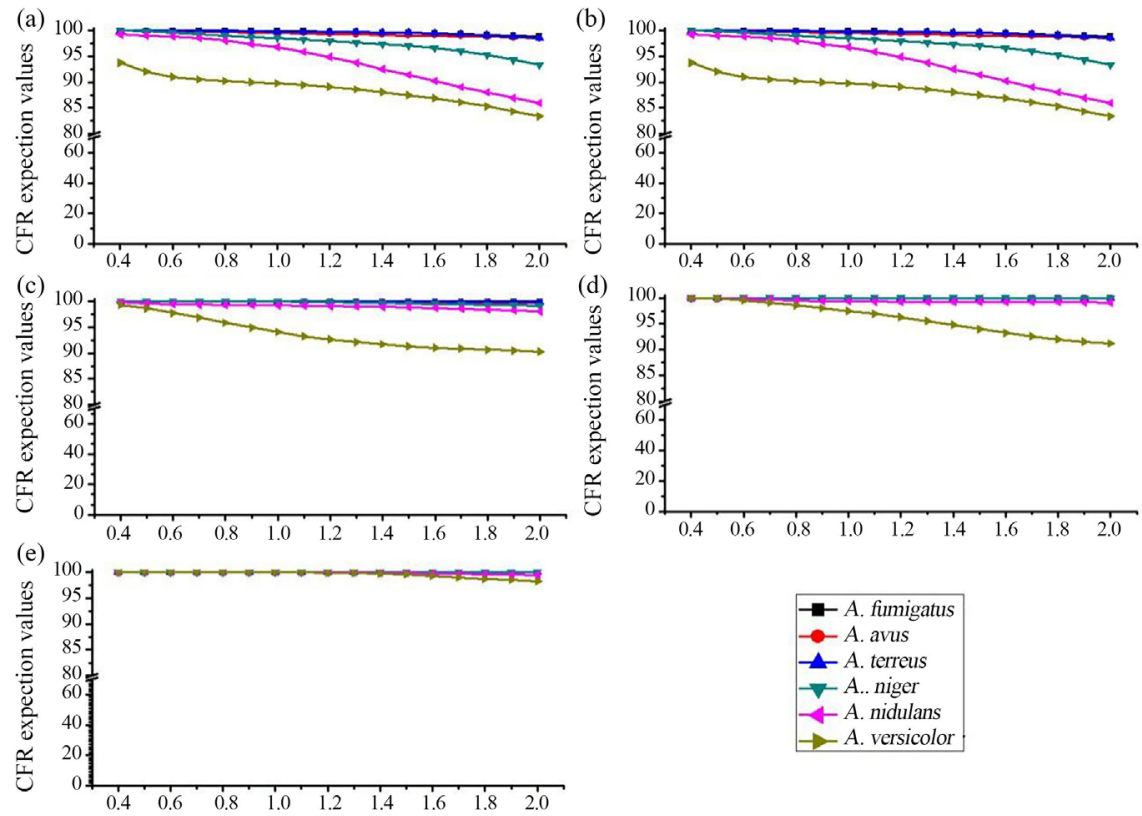

Figure 3. Cumulative fraction of response (CFR) expectation values of various posaconazole dosage regimens at various $f \mathrm{AUC}_{0-24} / \mathrm{MIC}$ (free-drug area under the plasma concentration-time curve from zero to $24 \mathrm{~h} /$ minimum inhibitory concentration) targets against six Aspergillus spp. (A. fumigatus, A. flavus, A. terreus, A. niger, A. versicolor, and $A$. nidulans) in children and adults. The X axis label was $f$ AUC0-24/MIC targets. (a) $120 \mathrm{mg} / \mathrm{m}^{2}$ tid; (b) $50 \mathrm{mg}$ bid; (c) $100 \mathrm{mg}$ bid; (d) $200 \mathrm{mg}$ bid; (e) $400 \mathrm{mg}$ bid. 
$A$. niger and $A$. nidulans). However, none of the simulated dosage regimens were effective against $C$. guilliermondii or $C$. krusei in children. Similarly, use of posaconazole doses of $50 \mathrm{mg}$ bid or $100 \mathrm{mg}$ bid was also ineffective against $C$. guilliermondii and C. krusei in adults. Increased doses (e.g. $200 \mathrm{mg}$ bid) against C. krusei in adults resulted in CFR values ranging from $83.15 \%$ to $94.80 \%$, demonstrating improved efficacy. This effect was not observed in C. guilliermondii. In addition, none of the posaconazole dosage regimens investigated achieved CFRs $>90 \%$ against $C$. glabrata. These results were consistent with MIC distributions that resulted in a CFR of $88.77 \%$ in C. glabrata (MIC range, 0.125 to 32 $\mu \mathrm{g} / \mathrm{ml})$.

Posaconazole is currently available as an oral formulation due to its poor aqueous solubility. Posaconazole oral suspension absorption is unpredictable and is often affected by concomitant medications and mucositis [27]. The compound achieves optimal exposure when administered in two to four divided doses with food or a nutritional supplement. For prophylaxis of invasive fungal infections, a $200 \mathrm{mg}$ tid dose of posaconazole is recommended. In a previous study, pediatric patients aged 13 years or younger with hematologic malignancy received prophylactic posaconazole oral suspension at a dose of $120 \mathrm{mg} / \mathrm{m}^{2}$ tid in comparison to the adult prophylactic dose of $200 \mathrm{mg}$ tid. To achieve the same antifungal efficacy, pediatric patients require a relatively higher dose of posaconazole than adults. The need for a relatively higher dose in pediatric patients is due to a higher clearance rate of the drug per kilogram of body weight compared to adults [27]. Currently, the recommended dosage regimen of posaconazole is $400 \mathrm{mg}$ twice daily with food for refractory oropharyngeal candidiasis or refractory invasive aspergillosis. In patients who cannot tolerate solid food, $200 \mathrm{mg}$ posaconazole should be administered four times daily with a nutritional supplement [27]. These clinical dosage regimens are consistent with the results that found CFR > 90\% (400 mg bid) against eight Candida spp. and six Aspergillus spp. in adults, and suggest that clinical use of this regimen is appropriate [28]. Dose adjustments are not necessary for patients with renal or hepatic dysfunction.

The appropriate $\mathrm{PK} / \mathrm{PD}$ parameters have been extensively characterized for posaconazole. $\mathrm{AUC}_{0-24} / \mathrm{MIC}$ is an important indicator of treatment efficacy. Numerous studies with antimicrobials have shown that an increased PK/PD index is necessary to be efficacious against organisms with reduced susceptibility to drug treatment. In vivo studies with posaconazole showed that free-drug $\mathrm{AUC}_{0-24} / \mathrm{MIC}$ ranged from 6.12 to 26.7 (mean \pm standard deviation, $16.9 \pm 7.8$ ) against Candida spp. and varied from 0.44 to 1.96 (mean \pm standard deviation, $1.09 \pm 0.63$ ) against Aspergillus spp. [20] [21]. However, differences in PK/PD target values between Candida spp. and Aspergillus spp. should be considered when evaluating the efficacy of posaconazole treatment. In the present study, various PK/PD target values of Candida spp. (6 - 30) and Aspergillus spp. (0.4 2) were used to calculate CFRs of different posaconazole dosage regimens in 
children and adults. FIG revealed that the probability of clinical success can be achieved for any given target values.

This is the first study to analyze the differences in CFR of posaconazole against Candida spp. and Aspergillus spp. in children and adults. However, there are some potential limitations to this study. First, the PK parameters of posaconazole were collected from a relatively small sample size of children and adults. In addition, an important weakness of the use of posaconazole oral solution is that there is not any data available regarding the PK parameters of intravenous or delayed-release oral formulations. Furthermore, this MCS analysis only considered serum pharmacokinetics, which could be useful for evaluation of bloodstream infections but not for other sites of infection such as tissue. Finally, antimicrobial use and local susceptibility should be considered when PK/PD modeling is applied to the predicted clinical outcome.

\section{Conclusion}

In conclusion, the results of PK/PD modeling and Monte Carlo simulations suggest that the currently approved high-dose regimen of posaconazole $(400 \mathrm{mg}$ bid) is sufficient to treat adults for fungal infections by Aspergillus spp. and Candida spp., with the exception of $C$. glabrata. In addition, we were able to determine that the dosage regimen of posaconazole $\left(120 \mathrm{mg} / \mathrm{m}^{2} \mathrm{tid}\right)$ in children was most likely to attain the requisite $\mathrm{PK} / \mathrm{PD}$ targets against Aspergillus spp. This was effective against Candida infections in children except $C$. glabrata, $C$. guilliermondii, and $C$. krusei. As such, further studies should focus on optimization of posaconazole dosage regimens to improve the probability of treatment success for specific fungal infections. Simulation by PK/PD modelling is a crucial tool with the potential to guide antibiotic therapy.

\section{Funding}

This work was funded by the Chengde Science and Technology Planning Project (No. 201701A086).

\section{Data Availability Statement}

All data generated or analyzed during this study are included in this published article.

\section{Conflicts of Interest}

The authors declare no conflict of interest.

\section{References}

[1] Al-Abdely, H.M., Alothman, A.F., Salman, J.A., Al-Musawi, T., Almaslamani, M., Butt, A.A., Al Thaqafi, A.O., Raghubir, N., Morsi, W.E. and Yared, N.A. (2014) Clinical Practice Guidelines for the Treatment of Invasive Aspergillus Infections in Adults in the Middle East Region: Expert Panel Recommendations. Journal of In- 
fection and Public Health, 7, 20-31.

http://www.ncbi.nlm.nih.gov/pubmed/24029495

https://doi.org/10.1016/j.jiph.2013.08.003

[2] Bassetti, M. and Bouza, E. (2017) Invasive Mould Infections in the ICU Setting: Complexities and Solutions. Journal of Antimicrobial Chemotherapy, 72, i39-i47.

http://www.ncbi.nlm.nih.gov/pubmed/28355466

https://doi.org/10.1093/jac/dkx032

[3] Drew, R.H., Townsend, M.L., Pound, M.W., Johnson, S.W. and Perfect, J.R. (2013) Recent Advances in the Treatment of Life-Threatening, Invasive Fungal Infections. Expert Opinion on Pharmacotherapy, 14, 2361-2374.

http://www.ncbi.nlm.nih.gov/pubmed/24050675

https://doi.org/10.1517/14656566.2013.838217

[4] Keating, G.M. (2005) Posaconazole. Drugs, 65, 1553-1567.

http://www.ncbi.nlm.nih.gov/pubmed/16033292

https://doi.org/10.2165/00003495-200565110-00007

[5] Sabatelli, F., Patel, R., Mann, P.A., Mendrick, C.A., Norris, C.C., Hare, R., Loebenberg, D., Black, T.A. and McNicholas, P.M. (2006) In Vitro Activities of Posaconazole, Fluconazole, Itraconazole, Voriconazole, and Amphotericin B against a Large Collection of Clinically Important Molds and Yeasts. Antimicrobial Agents and Chemotherapy, 50, 2009-2015. http://www.ncbi.nlm.nih.gov/pubmed/16723559 https://doi.org/10.1128/AAC.00163-06

[6] Dolton, M.J., Bruggemann, R.J., Burger, D.M. and McLachlan, A.J. (2014) Understanding Variability in Posaconazole Exposure Using an Integrated Population Pharmacokinetic Analysis. Antimicrobial Agents and Chemotherapy, 58, 6879-6885. http://www.ncbi.nlm.nih.gov/pubmed/25199779 https://doi.org/10.1128/AAC.03777-14

[7] Li, Y., Theuretzbacher, U., Clancy, C.J., Nguyen, M.H. and Derendorf, H. (2010) Pharmacokinetic/Pharmacodynamic Profile of Posaconazole. Clinical Pharmacokinetics, 49, 379-396. http://www.ncbi.nlm.nih.gov/pubmed/20481649 https://doi.org/10.2165/11319340-000000000-00000

[8] Krishna, G., Moton, A., Ma, L., Medlock, M.M. and McLeod, J. (2009) Pharmacokinetics and Absorption of Posaconazole Oral Suspension under Various Gastric Conditions in Healthy Volunteers. Antimicrobial Agents and Chemotherapy, 53, 958-966. http://www.ncbi.nlm.nih.gov/pubmed/19075045 https://doi.org/10.1128/AAC.01034-08

[9] Clark, N.M., Grim, S.A. and Lynch, J.P. (2015) Posaconazole: Use in the Prophylaxis and Treatment of Fungal Infections. Seminars in Respiratory and Critical Care Medicine, 36, 767-785. http://www.ncbi.nlm.nih.gov/pubmed/26398542 https://doi.org/10.1055/s-0035-1562902

[10] Xu, G., Zhu, L., Ge, T., Liao, S., Li, N. and Qi, F. (2016) Pharmacokinetic/Pharmacodynamic Analysis of Voriconazole against Candida spp. and Aspergillus spp. in Children, Adolescents and Adults by Monte Carlo Simulation. International Journal of Antimicrobial Agents, 47, 439-445.

http://www.ncbi.nlm.nih.gov/pubmed/27179818 https://doi.org/10.1016/j.ijantimicag.2016.02.016

[11] Koomanachai, P., Yungyuen, T., Disthaporn, P., Kiratisin, P. and Nicolau, D.P. (2016) Application of Pharmacodynamic Profiling for the Selection of Optimal Beta-Lactam Regimens in a Large University Hospital. International Journal of Infectious Diseases, 46, 22-26. http://www.ncbi.nlm.nih.gov/pubmed/27021531 https://doi.org/10.1016/j.ijid.2016.03.020 
[12] Xie, J., Wang, T., Sun, J., Chen, S., Cai, J., Zhang, W., Dong, H., Hu, S., Zhang, D., Wang, X. and Dong, Y. (2014) Optimal Tigecycline Dosage Regimen Is Urgently Needed: Results from a Pharmacokinetic/Pharmacodynamic Analysis of Tigecycline by Monte Carlo Simulation. International Journal of Infectious Diseases, 18, 62-67. http://www.ncbi.nlm.nih.gov/pubmed/24246741 https://doi.org/10.1016/j.ijid.2013.09.008

[13] Soon, R.L., Turner, S.J., Forrest, A., Tsuji, B.T. and Brown, J. (2013) Pharmacokinetic/Pharmacodynamic Evaluation of the Efficacy and Safety of Daptomycin against Staphylococcus aureus. International Journal of Antimicrobial Agents, 42, 53-58. http://www.ncbi.nlm.nih.gov/pubmed/23684388 https://doi.org/10.1016/j.ijantimicag.2013.02.009

[14] Canut, A., Isla, A., Betriu, C. and Gascon, A.R. (2012) Pharmacokinetic-Pharmacodynamic Evaluation of Daptomycin, Tigecycline, and Linezolid versus Vancomycin for the Treatment of MRSA Infections in Four Western European Countries. European Journal of Clinical Microbiology \& Infectious Diseases, 31, 2227-2235. http://www.ncbi.nlm.nih.gov/pubmed/22371294 https://doi.org/10.1007/s10096-012-1560-7

[15] Doan, T.N., Kong, D.C.M., Patel, K., Walker, P., Spencer, A. and Kirkpatrick, C.M.J. (2014) Comparison of the Probability of Target Attainment of Anidulafungin against Candida spp. in Patients with Acute Leukaemia. International Journal of Antimicrobial Agents, 44, 450-457.

http://www.sciencedirect.com/science/article/pii/S0924857914002556 https://doi.org/10.1016/j.ijantimicag.2014.07.019

[16] Mouton, J.W., Schmitt-Hoffmann, A., Shapiro, S., Nashed, N. and Punt, N.C. (2004) Use of Monte Carlo Simulations to Select Therapeutic Doses and Provisional Breakpoints of BAL9141. Antimicrobial Agents and Chemotherapy, 48, 1713-1718. https://www.ncbi.nlm.nih.gov/pubmed/15105125 https://doi.org/10.1128/AAC.48.5.1713-1718.2004

[17] Xu, G., Zhu, L., Liao, S., Ge, T. and Yang, J. (2015) Assessment of Echinocandin Regimens by Pharmacokinetic/Pharmacodynamic Analysis against Candida spp. in Paediatric Patients. International Journal of Antimicrobial Agents, 46, 631-641.

http://www.sciencedirect.com/science/article/pii/S0924857915003131 https://doi.org/10.1016/j.ijantimicag.2015.08.009

[18] Courtney, R., Pai, S., Laughlin, M., Lim, J. and Batra, V. (2003) Pharmacokinetics, Safety, and Tolerability of Oral Posaconazole Administered in Single and Multiple Doses in Healthy Adults. Antimicrobial Agents and Chemotherapy, 47, 2788-2795. http://www.ncbi.nlm.nih.gov/pubmed/12936975 https://doi.org/10.1128/AAC.47.9.2788-2795.2003

[19] Vanstraelen, K., Colita, A., Bica, A.M., Mols, R., Augustijns, P., Peersman, N., Vermeersch, P., Annaert, P. and Spriet, I. (2016) Pharmacokinetics of Posaconazole Oral Suspension in Children Dosed According to Body Surface Area. The Pediatric Infectious Disease Journal, 35, 183-188.

http://www.ncbi.nlm.nih.gov/pubmed/26544987 https://doi.org/10.1097/INF.0000000000000963

[20] Andes, D., Marchillo, K., Conklin, R., Krishna, G., Ezzet, F., Cacciapuoti, A. and Loebenberg, D. (2004) Pharmacodynamics of a New Triazole, Posaconazole, in a Murine Model of Disseminated Candidiasis. Antimicrobial Agents and Chemotherapy, 48, 137-142. http://www.ncbi.nlm.nih.gov/pubmed/14693531 https://doi.org/10.1128/AAC.48.1.137-142.2004

[21] Lepak, A.J., Marchillo, K., Vanhecker, J. and Andes, D.R. (2013) Posaconazole 
Pharmacodynamic Target Determination against Wild-Type and Cyp51 Mutant Isolates of Aspergillus fumigatus in an in Vivo Model of Invasive Pulmonary Aspergillosis. Antimicrobial Agents and Chemotherapy, 57, 579-585.

http://www.ncbi.nlm.nih.gov/pubmed/23147740 ttps://doi.org/10.1128/AAC.01279-12

[22] Liao, S., Ge, T., Zhu, L., Zhao, Y., Yang, J. and Xu, G. (2015) A Pharmacokinetic/Pharmacodynamic Analysis of a Standard Voriconazole Regimen in Different CYP2C19 Genotypes by Monte Carlo Simulation. Pharmazie, 70, 306-309. http://www.ncbi.nlm.nih.gov/pubmed/26062298

[23] Howard, S.J., Lestner, J.M., Sharp, A., Gregson, L., Goodwin, J., Slater, J., Majithiya, J.B., Warn, P.A. and Hope, W.W. (2011) Pharmacokinetics and Pharmacodynamics of Posaconazole for Invasive Pulmonary Aspergillosis: Clinical Implications for Antifungal Therapy. The Journal of Infectious Diseases, 203, 1324-1332.

http://www.ncbi.nlm.nih.gov/pubmed/21357943 https://doi.org/10.1093/infdis/jir023

[24] Mavridou, E., Bruggemann, R.J., Melchers, W.J., Mouton, J.W. and Verweij, P.E. (2010) Efficacy of Posaconazole against Three Clinical Aspergillus fumigatus Isolates with Mutations in the cyp51A Gene. Antimicrobial Agents and Chemotherapy, 54, 860-865. http://www.ncbi.nlm.nih.gov/pubmed/19917751 https://doi.org/10.1128/AAC.00931-09

[25] Cacciapuoti, A., Loebenberg, D., Corcoran, E., Menzel Jr., F., Moss Jr., E.L., Norris, C., Michalski, M., Raynor, K., Halpern, J., Mendrick, C., Arnold, B., Antonacci, B., Parmegiani, R., Yarosh-Tomaine, T., Miller, G.H. and Hare, R.S. (2000) In Vitro and in Vivo Activities of SCH 56592 (Posaconazole), a New Triazole Antifungal Agent, against Aspergillus and Candida. Antimicrobial Agents and Chemotherapy, 44, 2017-2022. http://www.ncbi.nlm.nih.gov/pubmed/10898669 https://doi.org/10.1128/AAC.44.8.2017-2022.2000

[26] Graybill, J.R., Bocanegra, R., Najvar, L.K., Luther, M.F. and Loebenberg, D. (1998) SCH56592 Treatment of Murine Invasive Aspergillosis. Journal of Antimicrobial Chemotherapy, 42, 539-542. http://www.ncbi.nlm.nih.gov/pubmed/9818757 https://doi.org/10.1093/jac/42.4.539

[27] Groll, A.H. and Lehrnbecher, T. (2008) Posaconazole for Paediatric Patients: Status of Development and Future Perspectives. Mycoses, 51, 5-11.

http://www.ncbi.nlm.nih.gov/pubmed/18721328 https://doi.org/10.1111/j.1439-0507.2008.01569.x

[28] Jones, R.N., Craig, W.A., Ambrose, P.G., Dudley, M.N. and Pottumarthy, S. (2005) Reevaluation of Enterobacteriaceae MIC/Disk Diffusion Zone Diameter Regression Scattergrams for 9 Beta-Lactams: Adjustments of Breakpoints for Strains Producing Extended Spectrum Beta-Lactamases. Diagnostic Microbiology and Infectious Disease, 52, 235-246. http://www.ncbi.nlm.nih.gov/pubmed/16105568 https://doi.org/10.1016/j.diagmicrobio.2005.02.006 